\title{
Buyers' Decisions in Online Social Networks Environment
}

\author{
Gheorghe Orzan, Camelia Delcea, Elisabeta loanas and Mihai Cristian Orzan
}

Bucharest University of Economic Studies, Bucharest, Romania

Correspondence should be addressed to: Camelia Delcea; camelia.delcea@yahoo.com

Received date: 16 October 2014; Accepted date: 26 December 2014; Published date: 22 December 2015

Copyright (C) 2015. Gheorghe Orzan, Camelia Delcea, Elisabeta loanas and Mihai Cristian Orzan

. Distributed under Creative Commons CC-BY 4.0

\begin{abstract}
Due to the advantages of social media in connecting businesses to end-consumers directly, in a timely manner and at a low cost, by facilitating various areas of marketing, such as promotions, marketing intelligence, sentiment research, public relations, marketing communications, product and customer management, social media has become the now-a-days business reality. Therefore, social media is based on advertisings and customers who are influenced by other customers' opinion. In this context, the customers' engagement becomes vital, while the main goal of the companies is to obtain it on the long run. For this, the present paper is analyzing the buyer's decisions in this whole new environment, generated by the online social networks. A case study is putted forward in order to present the obtained results and grey systems theory, one of the newest theories of the artificial intelligence area, is used for underlying them.
\end{abstract}

Keywords: advertising, marketing, social networks, grey systems, decisions.

\section{Introduction}

The spectacular development of recent year's technology has created new opportunities for communication industry and beyond. Therefore, communication has been reinvented with the appearance of the social media and subsequently used as a business tool.

Social media is characterized by user generated content, which has been found to be more effective than traditional marketing communications in influencing the attitudes and behaviours' of other users (Thackeray et al., 2008). Web 2.0 platform is the new technology that changed the way of communicating between users and also with the business medium.

Along with the development of Web 2.0 platform and then creating new technologies and mass the use of the Internet users have led to a new product - Social media. Social media, from the beginning was produced and used extensively by users. So Web 2.0 technologies have led to a new era of communication. Most common technologies are: social networks, blogs but also wikis.

Cite this Article as: Gheorghe Orzan, Camelia Delcea, Elisabeta Ioanas and Mihai Cristian Orzan (2015)," Buyers' Decisions in Online Social Networks Environment ", Journal of Eastern Europe Research in Business and Economics , Vol. 2015 (2015), Article ID 287625, DOI: 10.5171/2015.287625 
The consumer of information has gone from simple reader and commenter to content creator.

Web 2.0 technologies have had three effects a shift in the locus of activity from the desktop to the Web, a shift in the locus of value production from the firm to the consumer and a shift in the locus of power away from the firm to the consumer. (Parveen et al., 2014)

Social networks are a reality nowadays and have changed the way companies are managing their customer relationships. Two thirds of the world's internet users visit social networks, email activity that exceeds the top online activities. Also because of the interactive nature it made easier to improve communication with the consumers and also to receive a quick feedback about their online campaigns whether are social, political or advertising. Realizing the potential that social media has and the power it has on consumers, the companies build campaigns with the purpose to increase awareness among online consumers and to inform them about their new products and services. Companies use the online tools to attract users and to keep them permanently plugged into information using social networks like Facebook, Twitter, Google +, LinkeIn, etc.

There are various ways to communicate in the B2C medium and Leeflang et al., (2014) shows in the graphic below some of the current and future usage of the digital media tools. A it can be been the social media sites will have a high growth in the next 2-4 years. The other tools with which companies use to send messages or to create promotional advertising campaigns are: company home page, email, social media, mobile, search engines, mobile applications.

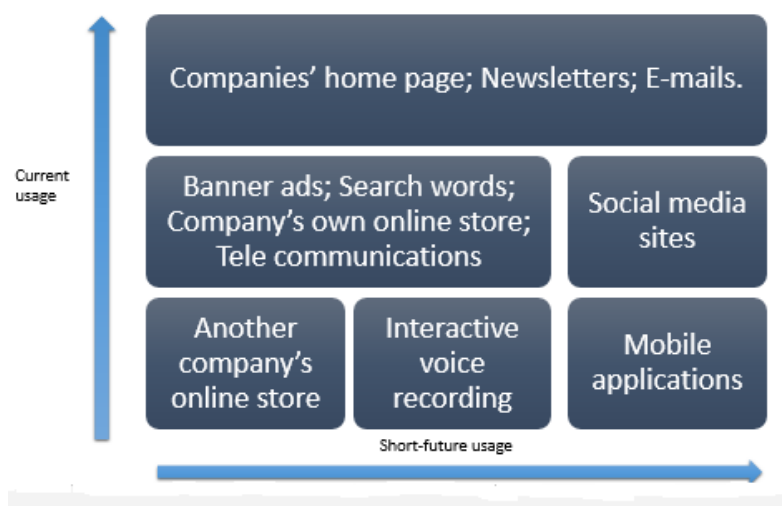

Figure 1: Current usage and future usage matrix of digital marketing tools (adapted after Leeflang et al., 2014).

Facebook is the most popular social network followed by Youtube. Facebook has transformed online communication in a major social phenomenon. Founded in 2004, this social network mainly aims to connect people. If in the past online communication was achieved mainly through email, Facebook now allows users to maintain existing relationships with friends, to reconnect with old friends, to organize social commitments, and to seek information (Ellison et al, 2013). Users usually join these networks for several reasons such as commenting pictures, statuses, posts and interact with their friends. (Holzner, 2009, Cox T, Park 2014) 
Social networks such as Facebook, Google+, Twitter, and have a significant impact on how users share and exchange information.

Online social networks are associated primarily with information and communication and less games or online shopping. Thus there is direct influence between online consumer's behavior online and a social network has on and has an even more impact in the company's digital strategies. For business, it means radically rethinking how they use the social media to promote their services / products, to strengthen their brands and relate to their target audience.

Due to the advantages of social media in connecting businesses to end-consumers directly, in a timely manner and at a low cost, by facilitating various areas of marketing, such as promotions, marketing intelligence, sentiment research, public relations, marketing communications, product and customer management, social media has become the centre of attention in many industries. (Parveen et al., 2014, Akar and Topcu, 2011, Kaplan and Haenlein, 2010). Hence social media content creates customers who are more influenced by other customers' opinion than by advertising posted on the online social networks. As a consequence, this will lead to other (marketing) orientations such as customer engagement (van Doorn et al., 2010), this being the main goal which the companies are struggling to obtain on the long run.

There were conducted several studies on advertising campaigns but most were on mobile advertising by authors like: e.g., Soroa-Koury, 2010, Chang and Thorson, 2004, Dijkstra, 2002, Cardarelli, \& de Montigny, 2007, and Havlena et al., 2007. They studied from several perspectives combinations of online campaigns but also in combination with the traditional environment, trying to see how perceptive the consumer is. Other studies tried to analyze the effectiveness of advertising campaigns like Hsieh and Chen, 2011 and
Yang 2006. The Hsieh and Chen, 2011, study provides a different perspective to relevant internet advertising companies on promoting products through banner ads. But according to this study, a company manager can consider establishing variable cost standards based on the content type provides a different perspective to relevant internet advertising companies on promoting products through banner ads.

The campaigns made through traditional media such as newspapers, magazines, and television did not interact with the consumers. Nowadays the social media receives a feedback from the consumer which can opt to avoid or to ignore online aggressive campaigns or campaigns that are not interesting for the consumer. In this way the consumer influences the social media campaigns and marketing strategies of the companies and the companies take into account the feedback received and uses to improve their image and services.

The more impact the internet has in the consumer's life the more open the consumer is to the social media campaigns. Consequently even though the consumer is influenced made by campaigns made through the traditional media (radio, television, newspapers, etc.) is more influenced by campaigns made through online social networks.

Campaigns conducted through online networks enable consumers in the first phase to be informed about the product or service, and to find whether it was purchased or recommended by a friend and then compare it with other similar products / services have the most positive comments. Blogs, product reviews, discussion groups, product ratings, etc. are also important sources of information describing how customers collect information, use that information, and how that information is used in their decision-making, shopping behaviour, and post-purchase behaviour (Mayzlin and Yoganarasinhan, 2012 and Onishi and Manchanda, 2012). 
Also the consumer is informed through the online campaigns revealed by his friends that have purchased the service/product. In this way the consumer takes the best buying decision optimal for him by balancing the appreciations and negative aspects posted in the social networks. Most of the times the a user sees an outdoor commercial, then when he sees it on TV, listen it to the radio, reads it in newspapers and in the end observes it on online.

This cycle can be reversed or mixed but in the end the consumer it's the one who decides to buy the product/service. It is really important that the companies that create advertising campaigns to implement integrated marketing campaigns because the consumer to notice the ad in the first medium may serve as a 'teaser' to attract attention to, arouse interest in, and increase curiosity for the ad in the second medium (Dijkstra et al., 2005, Edell and Keller, 1989, Edell and Keller, 1999 and Voorveld et al., 2011) and then maybe will take the decision to buy it.

In this study we research if there is a connection between the advertising campaigns on social media and decisions buyers are taking and which are the most used social networks by user.

\section{Grey Incidence Analysis}

Two categories of heading are defined: 'Heading' (Bold, Left, 12 pt) with 10 point space before paragraph for the first level headings and 'Subheading' (Italic, Left) for the subsidiary level.

Even though the time interval since the appearance of grey systems theory is short, approximately 30 years, their efficiency in resolving some of the problems that may arise has been already proven. As Andrew (2011) pointed in his research we live in a world in which the mathematical models used for analysing the surrounding world are not as robust as they may be. The author gives a small example regarding the way data are processing in these analyses: one of the main hypotheses in most of the studies is that the data have a normal of Gaussian distribution, while it is well known and accepted the fact that this kind of distribution are hard to find in the real world. Considering this small, but eloquent example and others more, Andrew concluded that "we live in a grey world". (Andrew, 2011)

Now, if someone is asking: "why a grey world?" the simplest response can be given by eliminating the other two possible approaches: living in a black word and living in a white world. These three possible situations are deeply stated in the control theory, where a black object is one totally unknown to the researcher while a white one is totally known. (Cotfas, 2013) Thinking of all the systems one can imagine is easy to demonstrate that none of these can be totally a black or a white system. From here, the only conclusion is that our entirely world is composed from grey systems, each of them having a smaller of a greater level of greyness, making it to be closer to a white or to a black state.

But the main characteristic of grey systems is determined by the fact that the methods and techniques employed have succeeded in offering to its users a great performance when analysing such grey systems. For this, it has been applied on a large array of domains, not necessarily from the economic field.

Among these techniques, the grey incidence analysis represents one of the main features grey systems theory offers. (Delcea, 2014)Through the grey incidence, the data sets are completely analysed and interpreted starting from the similitude degree between them, by calculating geometrical distances between their evolution graphics.

As the grey incidence analysis is still a dynamic component of the grey systems theory, there have been, over the time, a lot of approaches in determining this degree: 
- the absolute degree of grey incidence (Liu et. al., 2004);

- the relative degree of grey incidence (Liu et. al., 2004);

- the synthetic degree of grey incidence (Liu et al., 2004)

- the degree of grey B mode incidence (Wang, 1999);

- the degree of grey $\mathrm{C}$ mode incidence (Wang and Zhao, 1999);

- $\quad$ the degree of grey $\mathrm{T}$ mode incidence (Tang, 1995);

- the degree of grey slope incidence (Dang and Liu, 2004);

- $\quad$ the improved grey similarity degree (Sung and Dang, 2008);

- the periodic incidence degree (Shi et al., 2008), etc;
Having all these degrees of grey incidence, in this research the synthetic degree of grey incidence will be computed, as it has one of the highest applicability on small range of data.

The synthetic degree of grey incidence is calculated based on the following steps: (Liu et. al, 2004)

Notations: $\mathrm{X} 0$ and $\mathrm{Xj}, \mathrm{j}=1 \ldots \mathrm{n}$, with $\mathrm{t}=$ time period and $n=$ variables - two sequences of data with non-zero initial values and with the same length

Notations: $\mathrm{X} 0$ and $\mathrm{Xj}, \mathrm{j}=1 \ldots \mathrm{n}$, with $\mathrm{t}=$ time period and $n=$ variables - two sequences of data with non-zero initial values and with the same length

$$
\begin{aligned}
& X_{0}=\left(x_{1,0}, x_{2,0}, x_{3,0}, x_{4,0}, \ldots, x_{t, 0}\right), \\
& X_{j}=\left(x_{1, j}, x_{2, j}, x_{3, j}, x_{4, j}, \ldots, x_{t, j}\right),
\end{aligned}
$$

The images sequence is given by:

$$
X_{j}^{0}=\left(x_{1, j}-x_{1, j}, x_{2, j}-x_{1, j}, \ldots, x_{t, j}-x_{1, j}\right)=\left(x_{1, j}^{0}, x_{2, j}^{0}, \ldots, x_{t, j}^{0}\right)
$$

The initial values images of $\mathrm{X}_{0}$ and $\mathrm{X}_{\mathrm{j}}$ are:

$$
\begin{aligned}
& X_{0}^{\prime}=\left(x_{1,0}^{\prime}, x_{2,0}^{\prime}, \ldots, x_{t, 0}^{\prime}\right)=\left(\frac{x_{1,0}}{x_{1,0}}, \frac{x_{2,0}}{x_{1,0}}, \ldots, \frac{x_{t, 0}}{x_{1,0}}\right) \\
& X_{j}^{\prime}=\left(x_{1, j}^{\prime}, x_{2, j}^{\prime}, \ldots, x_{t, j}^{\prime}\right)=\left(\frac{x_{1, j}}{x_{1, j}}, \frac{x_{2, j}}{x_{1, j}}, \ldots, \frac{x_{t, j}}{x_{1, j}}\right)
\end{aligned}
$$

The zero-start points' images calculated based on (9) and (10) for $\mathrm{X}_{0}$ and $\mathrm{X}_{\mathrm{j}}$ are:

$$
\begin{aligned}
& X_{0}^{0^{\prime}}=\left(x_{1,0}^{\prime}-x_{1,0}^{\prime}, x_{2,0}^{\prime}-x_{1,0}^{\prime}, \ldots, x_{t, 0}^{\prime}-x_{1,0}^{\prime}\right)=\left(x_{1,0}^{\prime 0}, x_{2,0}^{0}, \ldots, x_{t, 0}^{\prime 0}\right) \\
& X_{j}^{0^{\prime}}=\left(x_{1, j}^{\prime}-x_{1, j}^{\prime}, x_{2, j}^{\prime}-x_{1, j}^{\prime}, \ldots, x_{t, j}^{\prime}-x_{1, j}^{\prime}\right)=\left(x_{1, j}^{\prime 0}, x_{2, j}^{\prime 0}, \ldots, x_{t, j}^{\prime}{ }^{0}\right)
\end{aligned}
$$

The computed absolute degree of grey incidence:

$$
\varepsilon_{0 j}=\frac{1+\left|s_{0}\right|+\left|s_{j}\right|}{1+\left|s_{0}\right|+\left|s_{j}\right|+\left|s_{0}-s_{j}\right|}
$$

with $\left|s_{0}\right|$ and $\left|s_{j}\right|$ determined by using the following formulas: 


$$
\begin{aligned}
& \left|s_{0}\right|=\left|\sum_{k=2}^{t-1} x_{k, 0}^{0}+\frac{1}{2} x_{t, 0}^{0}\right| \\
& \left|s_{j}\right|=\left|\sum_{k=2}^{t-1} x_{k, j}^{0}+\frac{1}{2} x_{t, j}^{0}\right|
\end{aligned}
$$

The relative degree of grey incidence:

$$
r_{0 j}=\frac{1+\left|s_{0}^{\prime}\right|+\left|s_{j}^{\prime}\right|}{1+\left|s_{0}^{\prime}\right|+\left|s_{j}^{\prime}\right|+\left|s^{\prime}{ }_{0}-s_{j}^{\prime}\right|}
$$

with $\left|s^{\prime} 0\right|$ and $\left|s^{\prime} j\right|$ calculated as:

$$
\begin{aligned}
& \left|s_{0}^{\prime}\right|=\left|\sum_{k=2}^{t-1} x_{k, 0}^{\prime 0}+\frac{1}{2} x_{t, 0}^{\prime 0}\right| \\
& \left|s_{j}^{\prime}\right|=\left|\sum_{k=2}^{t-1} x_{k, j}^{\prime 0}+\frac{1}{2} x_{t, j}^{0}\right|
\end{aligned}
$$

The synthetic degree of grey incidence is determined by both the absolute and the relative degrees of grey incidence:

$$
\rho_{0 j}=\theta \varepsilon_{0 j}+(1-\theta) r_{0 j}
$$

with $\mathrm{j}=2, \ldots, n, \theta \in[0,1]$ and $0<\rho_{0 j} \leq 1$.

Having this degree of grey incidence, in the next section, the data gathered through a questionnaire on the influence of advertising campaigns in social networks on buying decision are done and the results are largely presented and interpreted.

\section{Social Networks Case Study}

In terms of advertising campaigns' efficiency through social media on buyers' decisions, a questionnaire has been used containing both open and multiple choice questions. The structure of the questionnaire along with the received answers is presented in the next section.

\section{Survey}

First of all, the survey has started in June 2013 and was available online for a period of time equal to one month. After this period, the completion report shows that $93.02 \%$ of the respondents have filled it up entirely, while $6.98 \%$ of the respondents have only partially given answers to its questions.

Among the ones that have responded on all the questions, $97.67 \%$ have said that they have an account on a social media platform. Their distribution on the existing social media platforms is presented in Fig. 1. and it shows that the largest part of them $(31.78 \%)$ are using Facebook, followed by $22.48 \%$ users on YouTube, $17.83 \%$ on Google+, $14.73 \%$ on LinkedIn, $10.85 \%$ on Twitter and $2.33 \%$ on other social media platforms (such as: Pinterest, Stumbleupon, Goodreads, etc.) 


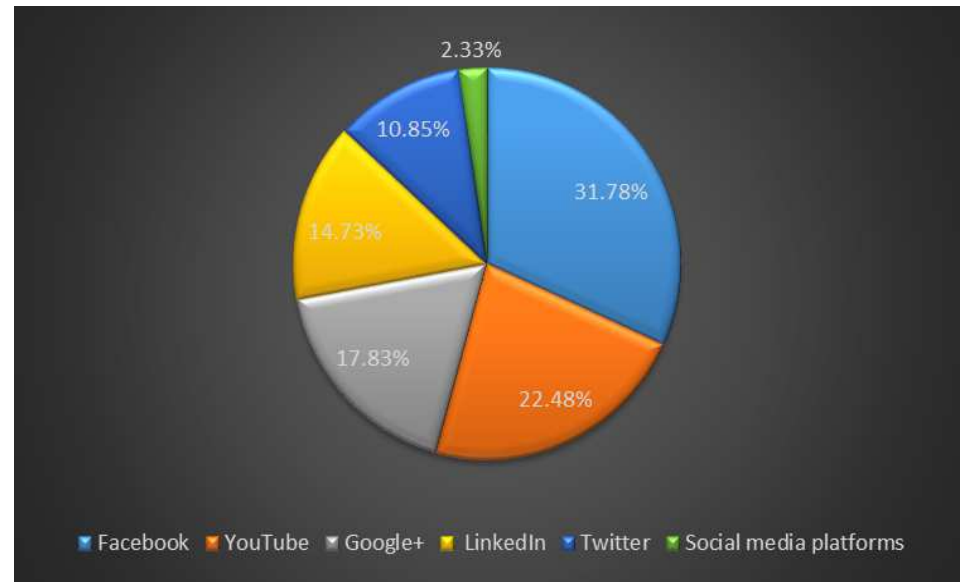

Figure 2: Respondents' distribution on social networks

Considering the respondents 'gender, $62.5 \%$ of them were women and $37.5 \%$ men, while their age was between 18 and 41 years old: $67.5 \%$ having between $18-23$ years old,
$22.5 \%$ between $24-29,5.00 \%$ between $30-35$ and $5.00 \%$ between $36-41$, as showed in Figure 2.

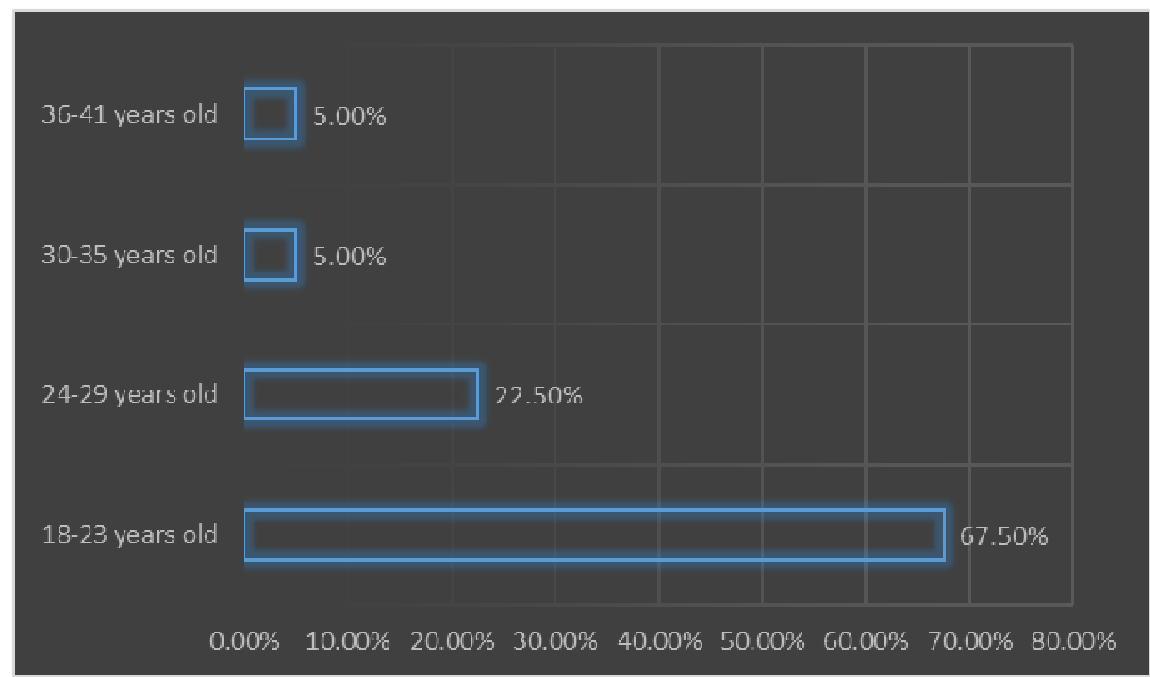

Figure 3: Respondents' age distribution

As for the advertising campaigns, $92.86 \%$ of the respondents said that they have seen a memorable campaign in the last 12 months, most of them naming social networks such as Facebook and YouTube as promoters for these advertisings.

Before seeing if there is a connection between the advertising campaigns on social media and decisions buyers are taking, it was important to know how important do the buyers think is a commercial in their case and which of the advertising channels they think is more appropriate for promoting a product. For this, a 5-point Likert scale was used, where 5 was considered very important, 4 - important, 3- moderately 
important, 2- of little importance and 1 unimportant and the respondents were asked to answer to the next question: "Please indicate the degree of importance for each of the following types of advertising: TV commercials, radio commercials, newspapers commercials and social media commercials." The answers are gathered in Table 1 and pictured in Figure 3.

Table 4: The importance of commercials

\begin{tabular}{|c|c|c|c|c|c|}
\hline & Unimportant & $\begin{array}{c}\text { Of little } \\
\text { importance }\end{array}$ & Important & $\begin{array}{c}\text { Moderately } \\
\text { important }\end{array}$ & $\begin{array}{c}\text { Very } \\
\text { important }\end{array}$ \\
\hline $\begin{array}{c}\text { Newspapers } \\
\text { commercials }\end{array}$ & $2 \%$ & $7 \%$ & $34 \%$ & $46 \%$ & $9 \%$ \\
\hline $\begin{array}{c}\text { Radio } \\
\text { commercials }\end{array}$ & $9 \%$ & $9 \%$ & $36 \%$ & $39 \%$ & $4 \%$ \\
\hline $\begin{array}{c}\text { Online/social } \\
\text { media } \\
\text { commercials }\end{array}$ & $2 \%$ & $7 \%$ & $46 \%$ & $7 \%$ & $36 \%$ \\
\hline $\begin{array}{c}\text { Outdoor } \\
\text { commercials }\end{array}$ & $2 \%$ & $7 \%$ & $46 \%$ & $17 \%$ & $26 \%$ \\
\hline $\begin{array}{c}\text { TV } \\
\text { commercials }\end{array}$ & $2 \%$ & $7 \%$ & $48 \%$ & $9 \%$ & $31 \%$ \\
\hline
\end{tabular}

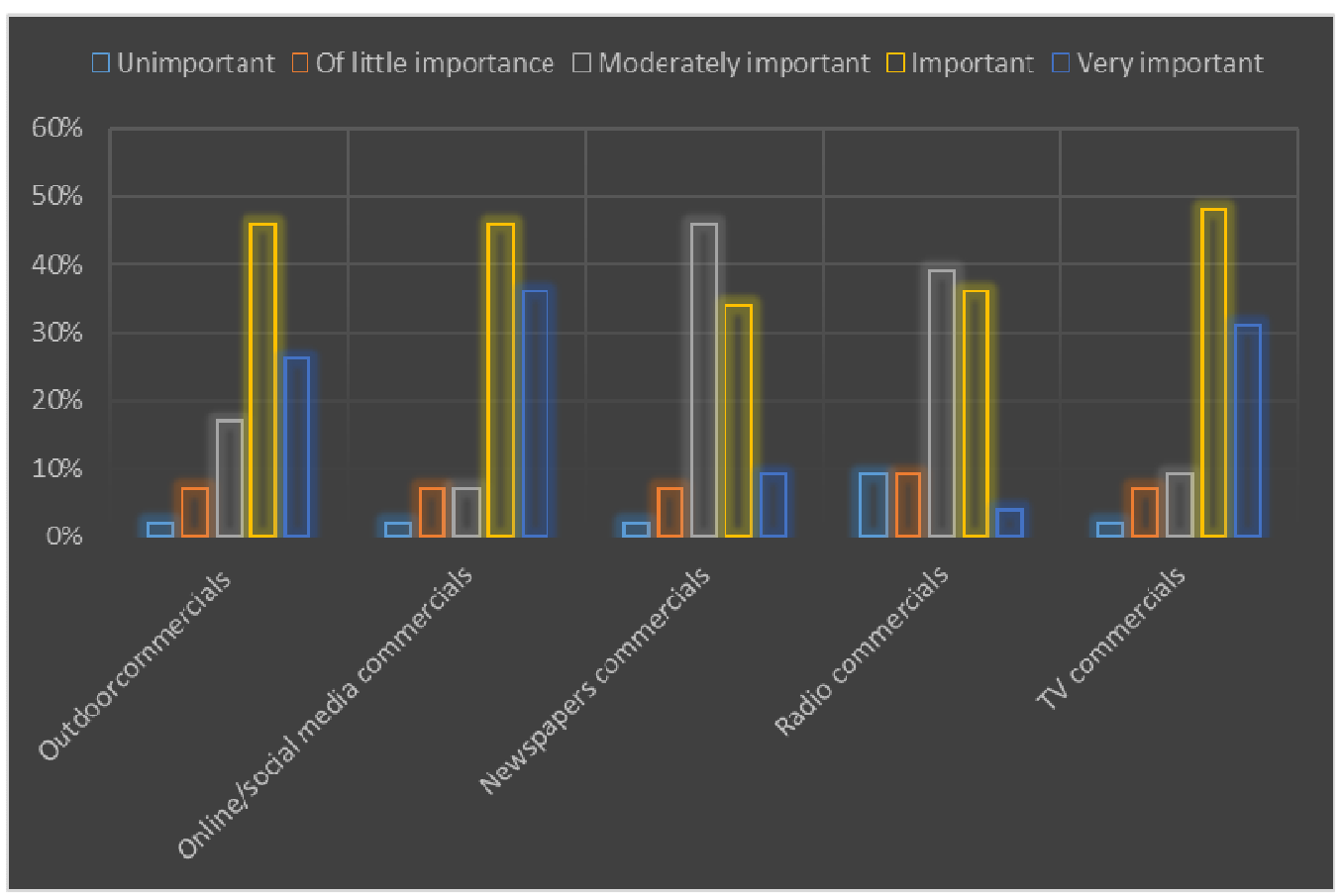

Figure 5: The importance of commercials' types

Gheorghe Orzan, Camelia Delcea, Elisabeta Ioanas and Mihai Cristian Orzan (2015), Journal of Eastern Europe Research in Business and Economics, DOI: 10.5171/2015.287625 
It can be observed that the respondents have considered that the importance of the commercials distributed through social media is very highly compared to other communication media, being followed by TV and outdoor commercials.

Another important aspect was the openness of the respondents to the social media campaigns. This issue was also measured using a 5-point Likert scale with 1- not open at all to such type of campaigns and 5 completely open. The respondents have said that they consider to be mostly open $(70.73 \%)$, indifferent $(26.83 \%)$ and reticent (2.44\%), proving once more these campaigns' efficiency.

Moreover, $82 \%$ of the respondents believed that is important to very important for any brand to have a profile on a social media platform, while $12 \%$ were indifferent to this aspect and 6\% thought that this is not an important issue.

Also, $61 \%$ of them said that the social media commercials are addressing to all age categories, 29\% weren't able to specify the age category, while $10 \%$ said that these are addressing especially to the young people.

As for the brands that the respondents are appreciating on social media, $80.49 \%$ of them have said that they are mostly following the brands they are used to or the brands their friends are following.

With all these considerations, the analysis can move further on the study of the impact that the advertising campaigns have on buyers' decisions, as it is presented in the next section. Here the elements taken from grey systems theory and exposed in section 2 are used for a better shaping of this relationship.

\section{Advertising Campaigns in Social Networks vs. Decisions}

For measuring the impact of the advertising campaigns in social networks on buyers' decisions a series of questions have been asked, among which two are mostly important:

- Think on the campaigns you have recently seen on social media and on the products that they promote. The message of the promotion campaigns stays in your memory:

- a day;

- a week;

- a month;

- $\quad$ more than a month;

- I forget it very quickly.

- Think on the same campaigns you have recently seen on social media and on the products that they promote. Regarding these products, you can say that in the last period you have bought them more often than usual.

- 1 - strongly disagree;

- 2 - disagree:

- 3 - undecided;

- 4 - agree;

- 5 - strongly agree.

On the first question, the answers were also quantified using a 5-point Likert scale (a day $=5$, a week $=4$, a month $=3$, more than a month $=2$ and I forget it very quickly $=1$ ), in order to apply the grey incidence analysis.

First of all, the absolute degree of grey incidence is computed using the grey systems modelling software (Liu et al., 2010, Liu et. al, 2012), the results being displayed in Figure 4. 


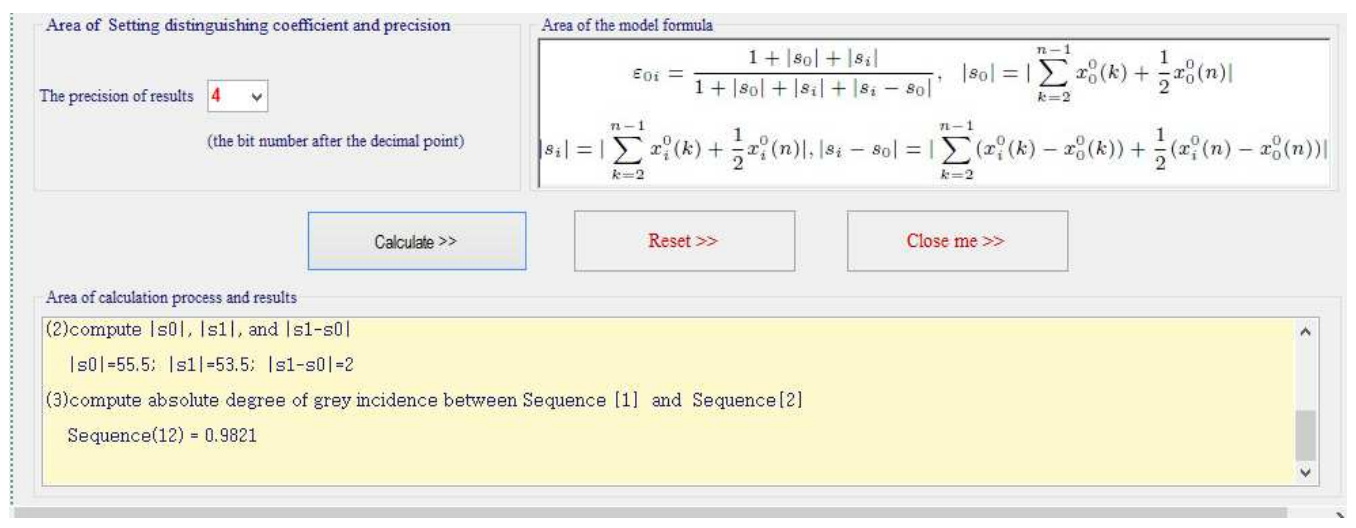

Figure 6: The absolute degree of grey incidence

On the same manner, the grey relative degree of grey incidence is computed. Fig. 5 is presenting the obtained results.

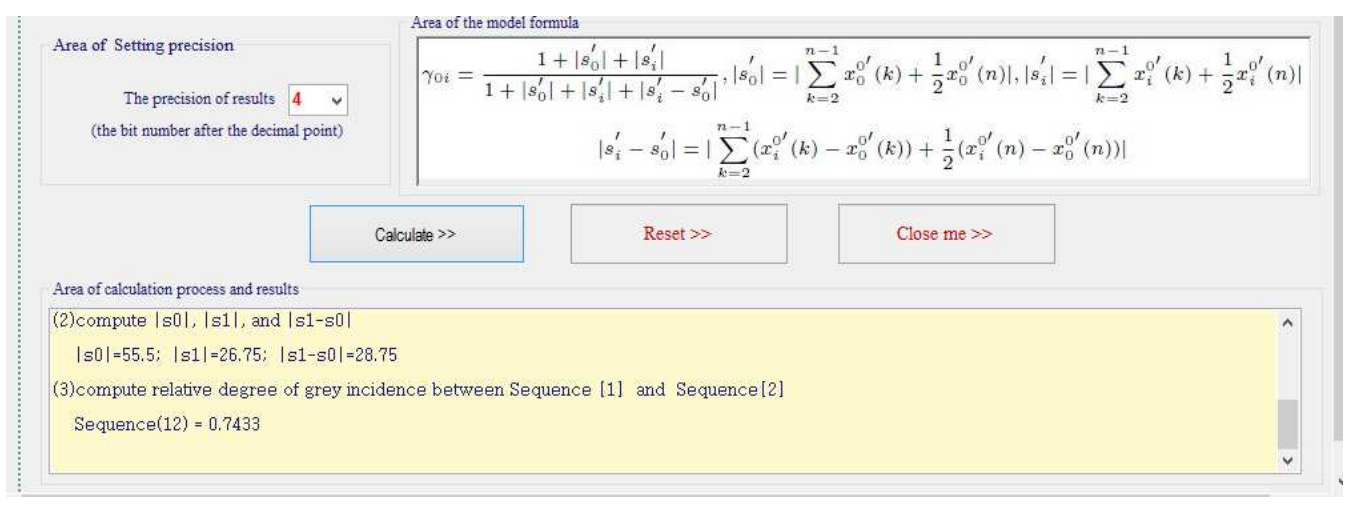

Figure 7: The relative degree of grey incidence

Having these two degrees of grey incidence, the synthetic degree of grey incidence can easily be computed and is approximately 0.8627 . This value shows an important and strong relationship between the promotion campaigns on social media and the buying decision taken by the persons that are receiving those campaigns.

Once more, it has been proven the strength of the linkage between these two elements, which opens new research areas such as: which of the products advertised on social media are best received by their buyers, what is the impact of the message received through these advertisings on the quantity bought, which are the elements that should be more emphasised in a commercial, how original there should be a commercial, how is the overall image of a product influenced by a social media commercial.

\section{Concluding Remarks}

The widespread adoption of digital marketing techniques, including social networks, has significantly contributed to the individualisation of marketing where the providers of goods and services are increasingly communicating with individual consumers and users, gaining feedback on a one-to-one basis and providing bespoke 
solutions for clients (Brady et al., 2008 and Simmons, 2008).

The social networks environment in which firms are promoting their products is having a great impact on their sales situation, mostly due to the impact their campaigns have on the buyers' decision. Also the effect of an integrated campaign over the advertisers, marketing managers and media planners will have interesting implications.

In this study, the nature of this relation has been studied using grey systems theory. For this, using a questionnaire, the perception of the buyers was shaped along with decisions they have made recently. The results were conclusive: there has been proven that there is a strong positive impact on the message expressed through marketing campaigns in social networks on the buyers' decisions. Even more, this study opens new research directions, as emphasised in section 3 .

\section{Acknowledgment}

This paper was cofinanced from the the European Social Fund, through the Sectorial Operational Programmee Human Resources Development 2007-2013, project number POSDRU/159/1.5/S/138907 "Excellence in scientific interdisciplinary research, doctoral and postdoctoral, in the economic, social and medical fields -EXCELIS", coordinator The Bucharest University of Economic. Also, this work was co-financed from the Studies European Social Fund through Sectoral Operational Programme Human Resources Development 2007-2013, project number POSDRU/159/1.5/S/134197 „Performance and excellence in doctoral and postdoctoral research in Romanian economics science domain".

\section{References}

1. Andrew, A., (2011), 'Why the world is grey', Grey Systems Theory and Application, 1 (2), 112-116.
2. Brady, M. and Fellenz, M.R., (2008), 'Researching the Role of Information and Communications Technology (ICT) in Contemporary Marketing Practices', Journal of Business \& Industrial Marketing, 23 (2), 108-114.

3. Chang, Y. and Thorson, E. (2004), 'Television and web advertising synergies', Journal of Advertising, 33 (2), 75-84

4. Cotfas, L.A. (2013), 'A finite-dimensional quantum model for the stock market', Physica A: Statistical Mechanics and its Applications, 392 (2), 371-380.

5. Cox, T. and Park, J.H., (2014), 'Facebook marketing in contemporary orthodontic practice: A consumer report', Journal of the World Federation of Orthodontists, 3 (2), e43e47.

6. Chang, Y. and Thorson, E. (2004), 'Television and Web Advertising Synergies', Journal of Advertising, 33 (2), 75-84.

7. Dang, Y.G. and Liu, S.F. (2004), 'Improvement degree of grey slope incidence', Engineering Science, 6 (3), 23-26.

8. Delcea, C., (2014), 'Not Black. Not even White. Definitively Grey Economic Systems', The Journal of Grey System, 26 (1), 11-25.

9. Dijkstra, M. (2002), 'An experimental investigation of synergy effects in multiplemedia advertising campaigns', University of Tilburg, Tilburg.

10.Dijkstra, M., Buijtels, H. and Raaij W., (2005). 'Separate and joint effects of medium type in consumer responses: A comparison of television, print, and the internet', Journal of Business Research, 58(3), 377-386.

11.Edell, J.A. and Keller, K.L., (1999), 'Analyzing media interactions: The effects of coordinated TV-print advertising campaigns', Marketing Science Institute, Cambridge, Massachusetts. 
12.Edell, J.A. and Keller, K.L., (1989), 'The information processing of coordinated media campaigns', Journal of Marketing Research, 26 (2), 149-163.

13.Ellison, N., Gray, R., Vitak, J., Lampe, C. and Fiore, A.,(2013), 'Calling All Facebook Friends: Exploring requests for help on Facebook'. In Proceedings of the 7th annual International Conference on Weblogs and Social Media. Washington, DC: Association for the Advancement of Artificial Intelligence.

14.Havlena, W., Cardarelli, R. and Montigny, M. (2007), 'Quantifying the isolated and synergistic effects of exposure frequency for TV, print, and internet advertising', Journal of Advertising Research, 47 (3), 215-221.

15. Holzner, S., (2009), 'Facebook marketing: leverage social media to grow your business'., IN: Que Publishing, Indianapolis.

16.Hsieh, Y.C. and Chen, K.H., (2011), 'How different information types affect viewer's attention on internet advertising', Computers in Human Behavior, 27 (2), 935-945.

17.Kaplan, A.M. and Haenlein, M., (1999), 'Users of the World, Unite! The Challenges and Opportunities of Social Media', Business Horizons, 53 (1), 59-68.

18.Leeflang, P.S.H., Verhoef, P.C., Dahlström, P. and Freundt, T., (2014), 'Challenges and solutions for marketing in a digital era', European Management Journal, 32 (1), 1-12.

19.Liu, S.F., Dang, Y.G. and Fang, Z.G., (2004), 'Grey system theory and its application', Science Press, Beijing.

20.Liu, S.F. and Lin, Y., (2010), 'Grey Systems - Theory and Applications, Understanding Complex Systems Series', Springer-Verlang, Berlin Heidelberg.

21.Liu, S.F., Forrest, J. and Yang, Y. (2012), 'A brief introduction to grey systems theory', Grey Systems: Theory and Application, 2 (2), 89-104.
22.Mayzlin, D. and Yoganarasinhan, H., (2012), 'Link to success: How blogs build an audience by promoting rivals', Management Science, 58 (9), 1651-1668.

23.Onishi, H. and Manchanda, P., (2012), 'Marketing activity, blogging and sales', International Journal of Research in Marketing, 29 (3), 221-234.

24.Paquette, D.E., (2009), 'Use of technology in the orthodontic practice: a day in the life', American Journal of Orthodontics and Dentofacial Orthopedics, 136 (4), 607-610.

25.Parveen, F., Jaafar, N.I. and Ainin, S., (2014), 'Social media usage and organizational performance: Reflections of Malaysian social media managers', Telematics and Informatics, 31 (3), 492-510.

26.Shi, X.H., Liu, S.F., Fang, Z.G. and Zhang, Q.S.,(2008), 'The Model of Grey Periodic Incidence and Their Rehabilitation', Chinese Journal of Management Science, 16 (3), 131136.

27.Simmons, G., (2008), 'Marketing to Postmodern Consumers: Introducing the Internet Chameleon'. European Journal of Marketing, 42 (3/4), 299-310.

28.Soroa-Koury, S. and Yang, K.C.C., (2010), 'Factors affecting consumers' responses to mobile advertising from a social norm theoretical perspective', Telematics Inform, 27 (1), 103-113.

29.Sung, Y. G. and Dang, Y.G., (2008), 'Improvement of Grey T Correlation Degree', Systems Engineering Theory and Practice, 28 (4), 135-139.

30.Tang, W.X., (1995), 'The concept and the computation method of T's correlation degree', Application of Statistics and Management, 14 (1), 34-37.

31.Thackeray, R., Neiger, B.L., Hanson, C.L. and McKenzie, J.F., (2008), 'Enhancing promotional strategies within social 
marketing programs: use of Web 2.0 social media', Health Promotion. Practice, 9 (4), 338-343.

32.Yang, K. (2006), 'According to this study, a company manager can consider establishing variable cost standards based on the content type', Telematics and Informatics, 23 (1), 3855.

33.Wang, Q.Y.,(1987), 'The Grey Relational Analysis of B-Model'. Journal of Huazhong University of Science and Technology, 17 (6), 77-82.
34.Wang, Q.Y. and Zhao, X.H., (1999), 'The Relational Analysis of C-Model', Journal of Huazhong University of Science and Technology, 27 (3), 75-77.

35.Van Doorn, J., Lemon, K.N., Mittal, V. Nass, N. Pick, P.C. Pirner, P. and Verhoef, C. (2010), 'Customer engagement behavior: theoretical foundations and research directions' , Journal of Service Research, 13 (3), 253-266.

36.Voorveld, H.A.M., Neijens, P.C. and Smit, E.G., (2011). 'Opening the black box: Understanding cross-media effects', Journal of, Marketing Communications, 17 (2), 69-85.

Gheorghe Orzan, Camelia Delcea, Elisabeta Ioanas and Mihai Cristian Orzan (2015), Journal of Eastern Europe Research in Business and Economics, DOI: 10.5171/2015.287625 